\title{
Employers' Role in the Improvement of Safety Level in Estonian Enterprises
}

\author{
Georgi Hrenov, Karin Reinhold, Piia Tint \\ Tallinn University of Technology
}

\begin{abstract}
The key persons in safety activities at enterprises are: top manager, his(her) representatives, working environment specialist, all acting for the employer; and working environment representatives, selected by the workers and holding the workers' rights in safety and health area. The main possibilities to improve the safety level in the firm have the working environment specialists, as they are usually educated and supported by the employer and the law. The current paper is looking for the possibilities to raise the employers' interest for improvement of their knowledge in safety and through this also the safety level in the workplace. Safety level in 12 Estonian enterprises was investigated using MISHA method (based on standard OHSAS 18001). Some of the firms have implemented OHSAS 18001 or belong to the foreign companies. The investigated enterprises were from different industries and agriculture firms. The safety level is very much depended on the owner of the firm. The larger the enterprise is the better are the possibilities to educate the employers and employees. One of the ideas to improve the safety level at enterprise is the method "learning through the interviews". The interview is worked out basing on MISHA method. The latter is a tool of quantitative study. The safety performance key elements were divided into three parts: formal, real, combined ones. Three hypothesis were formulated and the area in which they are proved concerning employer's activities were as follows: H1) Standard OHSAS 18001 has an impact on Formal safety performance in companies (p value< 0.013) - if OHSAS 18001 has been implemented, then: the assignment of tasks and responsibilities in OHS is committed to the top management, the employer is revising the safety policy, and the personnel's responsibilities in OHS are clearly defined. H2) Standard OHSAS 18001 has an impact on Real safety performance. ( $<<0.013)$ - if OHSAS 18001 is implemented, then: the top manager promotes dissemination of safety policy: the policy is made available to all of the personnel; resources for improvement are arranged by the top management; the top manager arranges meetings in OHS; there is a system for redesigning the workplaces for the persons who have difficulties in coping with the work. H3) Standard OHSAS 18001 has an impact on Combined safety performance $(p<0.007)$ - if OHSAS 18001 implemented, then: the top management is participating in the preparation of safety policy, top manager is reviewing the safety policy, is it operating effectively? He is informing the external bodies about the company's safety policy's effectiveness; the top manager arranges safety training for all of the personnel; there is a plan for reduction of accidents; it has been elaborated by the top manager; the company has a system for measuring the social climate in the company.
\end{abstract}

Keywords: employer's responsibilities in safety and health, occupational health and safety (OHS), safety and health management, safety in small and medium-sized enterprises, work environment.

\section{INTRODUCTION AND THEORETICAL PART}

The work environment is a large term and it occupies not only the physical work environment, but also the psychological and psychosocial elements that are depended on the people's character and attitudes. There are different key persons in the enterprise who have to take care of occupational health and safety (OHS): the employer, the working environment specialist (safety engineer) and working environment representatives. All these people have the possibility to improve the safety and health at workplaces. The roles of these key-actors in different countries are different [1], [2].

A safety management system in the standard OHSAS 18001 [3] is designed in order to deal with occupational health and safety (OHS) in a systematic way by the following activities: setting company's safety targets and objectives; designating roles and responsibilities for safety personnel; planning and performing the hazards mitigations; monitoring, measuring and improving the on-going system and its effectiveness [4]. Although the implementation of safety standards, particularly OHSAS 18001 usually declines the number of accidents and occupational diseases in the enterprises, it has not leaded to larger interest to use the OHS systems in some countries [5].

In the previous studies, the authors of the current paper have carried out the investigations in different workplaces [1], [2], [6], [7] and determined the nature of the real, formal and combined safety elements. The importance and possibilities to use the safety progress derived by the successful in OHS companies (e.g. enterprises which possess OHSAS 18001) for the companies without any systematic work in OHS was determined. The role of the workers' representation in OHS activities has been investigated [2]. The conclusion was: the position of safety representative has often a low status in the company; working 
environment specialists do not have enough time to fulfil their safety functions to keep employees safe. It was also postulated that the employers had limited understanding about the role of working environment representatives (WER). The WER are elected formally, there is no practical value of them. From this investigation arise the research questions of the current paper: how it is possible to enhance the interest of the employers towards safety matters and what role plays in this process OHSAS 18001 implementation? What are the main obstacles for the employers to show more interest against health and safety in managed by them companies?

There are different new models and methods for investigating the safety level at enterprises [8] - 10]. Gautam et al. [10] present a new scheme for measurement of safety performance in work systems using segmented point process models that can capture the points of changes in the working conditions as well as changes in safety activities. The findings of the case study application showed that the injury occurrences data fit the models for all accidents and first aid cases.

The risk assessment is one of the main areas, where the investigations are carried out and it is also very important and the basis for the development of safety and health improvements in the enterprises. Risk evaluation depends on the exposure limits established in the country [11] and also the international rules have to be followed [12]. In the study of Isik and Atasoylu [11], the main objectives were to determine the employer's awareness of the OHS law and to find out to what extent the employers fulfil their obligations to conduct risk assessments. This was possible through the interviews and written surveys of employers of small and medium-sized enterprises. One of the hypothesis in the paper [11] postulated that risk assessments are ineffective. The hypothesis was not approved: on the contrary, the risk assessment are always effective if reasonable limitations are settled.

New tool for risk assessment (RA) of psychological risks is presented recently. This area has been always the hardest area in RA. A novel approach is presented by Kyaw-Myint et al. [13] to identify critical exposure levels or health-based benchmarks of job control using the benchmark dose (BMD) method, which enables to determine the critical exposure levels for job control.

The current study is mainly dedicated to small and medium-sized enterprises, where there are fewer resources to improve the safety and health [14].

The OHS activities in the Nordic countries are organized [15], combining a top-down and bottom-up approach to the organization of OHS activities. The overall responsibilities rests with the employer, who seeks for the support both from the professional staff and from the participants in the OHS organization of the company.
The MISHA method [16] has four areas: A) organization and administration, B) participation, communication, and training; C) work environment, D) follow-up (accidents investigation etc.).

The safety key elements in MISHA method are divided into three parts: formal safety elements, like safety documents, content of the policy $(\mathrm{R}=0.895$ : the correlation between the safety activities and the implementation or non-implementation of OHSAS $18001)$, revising the safety policy $(\mathrm{R}=0.972)$, written safety policy $(\mathrm{R}=0.964)$, assignment of tasks and responsibilities $(\mathrm{R}=0.885)$.

The real safety elements include the top management's, line management's and supervisor safety knowledge, their commitment to the safety policy, communication, participation in workplace design etc. In this part of the key elements, OHSAS 18001 implementation influences on the resources ( $\mathrm{R}=0.968$ ), top management's commitment to the safety policy $(\mathrm{R}=0.964)$, and the dissemination of the safety policy $(\mathrm{R}=0.929)$.

In the part of combined safety, OHSAS 18001 has the strongest influence on the safety policy $(\mathrm{R}=0.888)$, workplace hazard analysis $(\mathrm{R}=0.737)$ and assessment of the work environment $(\mathrm{R}=0.805)$ [1].

Very often the enterprises implement integrated management system: ISO 9000, ISO 14000 and OHAS 18001 [17] are all taken into consideration.

\section{MATERIAL AND METHODS}

Twelve Estonian enterprises (Table 1) were examined with modified MISHA method [16] for clarifying the role of the employers in OHS matters as well as for studying the perspectives to improve the safety level of the enterprise through more effective employers' activities.

The enterprises were from the manufacturing industry (chemical, plastic, food and metal), construction, agriculture and transport. These enterprises agreed to carry out the MISHAquestionnaire-based investigation (the length of the questioning is over 2 hours).

Four (4) of the enterprises (group 1) had implemented OHSAS 18001, three (3) were belonging to the foreign corporations (group 2), in the last their own rules on safety were compulsory and implemented and five (5) enterprises represented the locally owned companies who had not implemented OHSAS 18001 (group 3, some of them even did not have knowledge about existing OHSAS 18001).

The qualitative study was carried out in these 12 companies in the form of interviews of employers (active managers, production managers). The interviewing of the employers gives the information about the present and possible role of the managers. The interviews were assessed by the first author of the paper. The interviews were taken as the basis for the quantitative study. 
For assessment to the MISHA questionnaire, the Likert scale (1- poor, 2- average, 3- good, 4- very good, 5- excellent) was used.

The questions from the MISHA questionnaire that concern the employers' activities, analysed in the current study, are as follows:

A1.2. Top management commitment to the safety policy: has company's top management (factory manager, managing director) committed itself to the goals of the policy? Is the commitment visible in the management's everyday activities?

A1.4. Assignment of tasks and responsibilities: are the tasks and responsibilities assigned to the top management?

A1.5. Participation in the preparation of the policy: has the top management participated in the preparation of the safety policy?

A1.6. Initial status review: is the current safety management system operating effectively?

A1.7. Safety documents: the employer is responsible? Are the responsibilities shared by the employer?

A1.8. Revising the safety policy: has the employer defined, how often the policy is revised?

A1.9. Dissemination of the policy: has the company defined how the policy is made available to the personnel? How the revised versions of the policy are distributed?

A1.10. Informing external bodies about the company's safety policy (how the temporary workers, sub-contractors, clients can have access to the company's safety policy)?

A1.11. Safety policy's connections to the company's other activities (to the company's quality and environmental policy).

A2.1. The top management's safety knowledge (is the top management aware of OHS implementation in the company, what are the indicators of OHS in the company?)

A2.4. Does the company has a safety committee or some other cooperative safety teams? Does the employer is included to the safety committee and does he take part in the meetings?

A2.8. Resources: does the company has the resources for OHS improvement?

B2.1. Does the manager arrange the information meetings on OHS?

B3.1. Does the employer affords the safety training for all the personnel on a regular basis?

C2.3. Does the personnel's responsibilities and authorities are clearly defined?

C3.1. Are the workplace risk analysis carried out on a regular basis? Are the results looked through by the manager? Are the reduction means financed by the manager?

C3.2. Does the top manager enters into a contract with the occupational health services? Does he reviews the results of the medical examinations?
C3.3. Does the activities of the safety organization are discussed with the top management?

D1.1. Does the top manager is aware of the statistics on work accidents and occupational diseases?

D1.2. The reduction of accidents: has the plan been elaborated and presented to the top manager?

D1.3. Does the company make statistics on absenteeism rates and summaries on absenteeism causes? Are the statistics available to the top management?

D2.1. Does the company has the system for redesigning the work or workplace of a person who has difficulties in coping with the work?

D2.2. Does the company measure the employees' mental work ability on a regular basis? Is the manager aware of the results?

D3.1. Does the company have a system for measuring the social climate (social relations between the workers if some problems have observed)?

The statistics used in the paper involved IBM SPSS Statistics 22.0 and R.2.15.2. The following statistical methods were used: correlation, MANOVA, factor analysis, principal component method, independent T-test [18].

\section{RESULTS}

The results of the quantitative analysis are given in Table 1. In the second column the characterization of the investigated enterprises is given. The interviews in the companies were carried out with the employer (if it was possible), but mainly with the production manager, who was mainly present in the workplace from the top management representatives (column 5). The total average score by MISHA method is presented in column 6 .

The total MISHA score for the companies of group 1 was 78-92; for the group 2 it was 75-86; for the group 3 the total score was 46-65 from the 100 possible. It shows that the implementation of OHSAS 18001 helps to upgrade the safety level at enterprises. The corporated companies also have their own rules to keep the safety and health matter on a comparatively high level.

The safety key elements mostly correlated with the employers' activities at enterprises in the safety and health area are presented in Table 2, 3, 4 (column 1). The results of the statistics between these connections in the real, formal and combined safety area (sum of squares by KMO and Barlett's test and $p$ value are presented in the columns 2 and 3 ).

\section{A.Hypothesis $\mathrm{HI}$}

Factor analysis were carried out with KMO and Bartlett's test [18]. The alpha correction (ANOVAs with Tukey's HSD post-hoc tests) was implemented and so the H1, H2, and H3 were confirmed. Three hypothesis were formulated and the area in which they are proved concerning employer's activities were as follows: 
H1) Standard OHSAS 18001 has an impact on formal safety performance in the companies. If OHSAS 18001 is implemented, then: the assignment of tasks and responsibilities in OHS is committed to the top management $(p=0.000)$, the employer is revising the safety policy $(p=0.000)$, the personnel's responsibilities and authorities in OHS are clearly defined $(p=0.013)$. The lower $p$-value $(p=0.072)$ have the following activities, which are dependent on the top manager's activities: the top manager is aware about the statistics of accidents and occupational health diseases and the rates of absenteeism are not directly committed to the manager. These obligations are usually more directed to the safety manager in the company, if the company has the job of safety engineer or working environment specialist. The small enterprises have no resources to hire the safety manager, therefore these obligations have to be held by the manager him(her)self. The lowest score ( $p=0.241)$ have the safety documents responsibility, these documents are usually hold also by the safety manager, particularly in medium-sized companies.

Table 1

The Characterization and Results of Quantitative Study by MISHA Method in Investigated Enterprises (N=12)

\begin{tabular}{|c|c|c|c|c|c|}
\hline Id.of the company & The activity area & Size, employees & \begin{tabular}{|l} 
OHSAS \\
company \\
/corporated \\
company
\end{tabular} & The person interviewed & Total score (100 max) \\
\hline 1 & 2 & 3 & 4 & 5 & 6 \\
\hline I & Chemical industry & $50-249$ & +1 & $\begin{array}{l}\text { Management's representative, } 45 \text {; } \\
\text { External auditor, } 34\end{array}$ & $\begin{array}{l}87 \\
78\end{array}$ \\
\hline II & Chemical industry & $50-249$ & +1 & $\begin{array}{l}\text { Management's representative, } 55 \\
\text { External auditor, } 34\end{array}$ & $\begin{array}{l}88 \\
78\end{array}$ \\
\hline III & Metal industry & $50-249$ & $-/-$ & $\begin{array}{l}\text { Management's representative, } 40 \\
\text { External auditor, } 53\end{array}$ & $\begin{array}{l}61 \\
50 \\
\end{array}$ \\
\hline IV & Metal industry & $>250$ & $-/+$ & Trade union representative, 60 & 86 \\
\hline V & $\begin{array}{l}\text { Agriculture farm } \\
\text { (milk production) }\end{array}$ & $<50$ & $-/-$ & Employer, 50 & 46 \\
\hline VI & $\begin{array}{l}\text { Agriculture farm } \\
\text { (grain production) }\end{array}$ & $<50$ & $-/-$ & Employer, 56 & 60 \\
\hline VII & Construction & $<50$ & $-/-$ & Active manager, 40 & 50 \\
\hline VIII & Transport & $50-249$ & $-1-$ & Personnel manager, 45 & 65 \\
\hline IX & Plastic industry & $50-249$ & +1 & Quality manager, 41 & 78 \\
\hline $\mathrm{X}$ & Electronics & $>250$ & $1+$ & Quality manager, 35 & 84 \\
\hline XI & Electronics & $>250$ & +1 & Quality manager, 59 & 92 \\
\hline XII & Food industry & $>250$ & $1+$ & Safety manager, 62 & 75 \\
\hline
\end{tabular}

Table 2

Correlation Between the Formal Safety Key Elements Hypothesis H1

\begin{tabular}{|l|l|l|}
\hline \multicolumn{1}{|c|}{ Safety key element } & \multicolumn{1}{|c|}{$\begin{array}{c}\text { SUM of squares } \\
\text { (KMO) and Barlett's test }\end{array}$} & \multicolumn{1}{|c|}{\begin{tabular}{l}
-value \\
\hline A1.4. Assignment of tasks and responsibilities to the top management
\end{tabular}} \\
\hline A1.7. Safety documents: the employer is responsible? & 13.375 & .000 \\
\hline $\begin{array}{l}\text { A1.8. Revising the safety policy: has the employer defined how often the policy } \\
\text { is revised? }\end{array}$ & 25.688 & .241 \\
\hline C2.3. Does the personnel's responsibilities and authorities are clearly defined? & 4.576 & .000 \\
\hline $\begin{array}{l}\text { D1.1. Does the top manager is aware of the statistics on the work accidents and } \\
\text { occupational diseases? }\end{array}$ & 21.007 & .013 \\
\hline $\begin{array}{l}\text { D1.3. Does the company make statistics on absenteeism rates and they are } \\
\text { available to the top management? }\end{array}$ & 5.458 \\
\hline
\end{tabular}

Table 3

Correlation Between the Real Safety Key Elements Hypothesis H2

\begin{tabular}{|c|c|c|}
\hline Safety key element & $\begin{array}{c}\text { SUM of squares } \\
(\text { KMO) and Barlett's test }\end{array}$ & $p$-value \\
\hline $\begin{array}{l}\text { A1.9. Dissemination of the policy: has the employer defined how the policy is } \\
\text { made available to the personnel? }\end{array}$ & 21.007 & .000 \\
\hline A2.1. Top management's safety knowledge & 3.005 & .039 \\
\hline A2.8. Resources: does the company has the resources for OHS improvement? & 22.688 & .000 \\
\hline $\begin{array}{l}\text { B2.1. Does the manager arrange the information meetings to the employers on } \\
\text { OHS? }\end{array}$ & 2.896 & .006 \\
\hline $\begin{array}{l}\text { D2.1. Does the company has the system for redesigning the work or workplaces } \\
\text { of a person with disabilities? }\end{array}$ & 0.047 & .013 \\
\hline $\begin{array}{l}\text { D2.2. Does the company measure the employees' mental work ability on a } \\
\text { regular basis? Is he aware of the results? }\end{array}$ & 1.188 & .148 \\
\hline
\end{tabular}


Environment. Technology. Resources, Rezekne, Latvia Proceedings of the $11^{\text {th }}$ International Scientific and Practical Conference. Volume I, 115-120

Table 4

Correlation Between the Combined Safety Key Elements Hypothesis H3

\begin{tabular}{|l|l|l|}
\hline \multicolumn{1}{|c|}{ Safety key element } & \multicolumn{1}{|c|}{$\begin{array}{c}\text { SUM of squares } \\
\text { (KMO) and Barlett's test }\end{array}$} & .001 \\
\hline $\begin{array}{l}\text { A1.6. Dissemination of the policy: has the employer defined how the policy is } \\
\text { made available to the personnel? }\end{array}$ & 13.375 & .001 \\
\hline A1.10. Informing external bodies about the company's safety policy & 17.241 & .214 \\
\hline $\begin{array}{l}\text { A2.4. Does the company has a safety committee or some other cooperative } \\
\text { safety teams? }\end{array}$ & 3.200 & .004 \\
\hline $\begin{array}{l}\text { B3.1. Does the employer affords the safety training for all the personnel on a } \\
\text { regular basis? }\end{array}$ & 2.854 & .340 \\
\hline $\begin{array}{l}\text { C3.2. Does the top manager enter into a contract with the occupational health } \\
\text { services? }\end{array}$ & 0.611 & .143 \\
\hline $\begin{array}{l}\text { C3.3. Does the activities of the safety organization are discussed with the top } \\
\text { management? }\end{array}$ & 1.965 \\
\hline $\begin{array}{l}\text { D1.2. The reduction of accidents: has the plan elaborated and presented to the } \\
\text { top manager? }\end{array}$ & 4.125 & .007 \\
\hline D3.1. Does the company have a system for measuring social climate? & 19.125 \\
\hline
\end{tabular}

\section{B. Hypothesis $\mathrm{H} 2$}

H2) Standard OHSAS 18001 has an impact on real safety performance in companies. If OHSAS 18001 is implemented, then: the top manager promotes dissemination of the safety policy: the policy is made available to all the personnel $(p=0.001)$; the resources for improvement of OHS activities are arranged by the top management $(p=0.000)$; the top manager arranges meetings in OHS $(p=0.006)$; in the company there is a system for redesigning the workplaces for the persons who have difficulties in coping with the work $(p=0.013)$. The top management's safety knowledge has to be advanced continuously. The employees' mental work ability is not measured even in OHSAS 18001 implemented companies $(p=0.39)$. This standard OHSAS 18001 has to be modified in this area.

C. Hypothesis $\mathrm{H} 3$

H3) Standard OHSAS 18001 has an impact on combined safety performance. If OHSAS 18001 has been implemented, then: top management is participating in the dissemination of the safety policy $(0.001)$, top manager is reviewing the safety policy, is it operating effectively? $\mathrm{He}$ is informing of the external bodies about the company's safety policy $(p=0.001)$; the top manager arranges safety training for all the personnel $(p=0.004)$; there is a plan for the reduction of accidents: it has been elaborated by the top manager $(p=007)$; the company has a system for measuring the social climate in the company $(p=0.000)$. OHSAS 18001 does not influence on the organizing the safety committee work $(p=0.214)$ and the top manager is not making the contract with the occupational health services influenced by OHSAS $18001(p=0.340)$; not all activities in the safety area are consulted with the top management $(p=0.143)$. OHS

D. Comments to top management's activities in

Usually the incorporation to the foreign firms influences positively to the management's attitudes to the safety activities. In one of the investigated firms, after the incorporation, the management started to implement the corporation-based safety system and first, the safety audit was conducted.

The result was: safety did not came important at once. Safety took the first priority only 10 year after the incorporation. After that, quality was emphasized even more. Now it could be said that "safety comes first".
The working environment representative's comments:

1. "The management's attitude to safety has not reached the ordinary workers yet. We have not really understood that safety is the priority in our department. Often we feel we have to rush in order to meet the production deadlines. Yes, we know that management declares safety is very important, but in practice, there are some safety flaws occurring. I personally work with an out-dated equipment and there is no hope to receive new one in near future".

2. The other WER from the same company, however, presents a slightly different opinion: "I think the safety level in our company is very good compared to my first employer. Here, everything concerning safety, is documented."

So, there are different perceptions on safety, concerning industrial workers. In OHSAS 18011 implemented companies they have more knowledge on safety matters compared for example with small enterprises were even the manager does not know that the Occupational Health and Safety act [19] exists in Estonia.

\section{DISCUSSION}

Our study revealed that management plays an essential role in OHS improvement in the company. By O'Toole [21], it is also postulated that the leadership's position is influencing the employee's perceptions of the safety management systems. Those perceptions appear to influence on the employee's decisions that relate to at-risk behaviours and decisions on the job. Organizational commitment did affect the perceived safety at work, but not on work accidents [21].

In the current study, it was declared that the plan for reduction of accidents if it is worked out by the employer, has very strong influence on the combined safety at enterprises. If the Standards (OHSAS 18001 etc.) are implemented then the organizational climate will also be better [22]. 
In the current study the implementation of OHSAS 18001 has a strong impact on the improvement of safety level at enterprises.

\section{CONCLUSIONS}

The hypothesis H1, H2, H3 on the influence of the firm type (OHSAS-implemented or nonimplemented) has an impact on the employer's activities in occupational safety and health area.

The general conclusion is: if the standard OHSAS 18001 is implemented, then then the OHS tasks and responsibilities are under the surveillance of the top manager. The employer is always revising the safety policy, the safety policy is available to every worker, the top manager arranges the OHS meetings if needed and the top manager is participating in the work-out of the safety policy, he(she) is continuously reviewing the policy, policy is effective and training in OHS is available to every worker.

The employer is in the key position in the enterprise in occupational safety and health improvement means and also it is positive if he has the resources to perform the changes. The three investigated small enterprises (the number of the workers under 50), the safety knowledge of the active manager is extremely important.

\section{REFERENCES}

[1] Õ. Paas, "Development of the safety management system at enterprises," PhD Thesis, Tallinn University of Technology, Tallinn, Estonian, pp. 164, 2015.

[2] G. Hrenov, Õ. Paas, P. Tint, and K. Reinhold, "Workers' representatives in OHS activities: example of Estonian industrial sector," Agronomy Research, vol. 14, no. 2, pp. 377-391, 2016.

[3] OHSAS 18001:2007. Occupational health and safety management standard. British Standardization Board.

[4] L. S. Robson, and P. L. Bigelow, "Measurement properties of occupational health and safety management audits: a systematic literature search and traditional literature synthesis," Can/Public Health, vol.101 (Suppl. 1), pp. 534540, 2010.

[5] Y. Kim, J. Park, M. Park, "Creating a culture of prevention in occupational safety and health practice," Safety and Health at Work, vol. 7, pp .89-96, 2016.

[6] Õ. Paas, K. Reinhold, and P. Tint, "Estimation of safety performance by MISHA method and the benefits of OHSAS 18001 implementation in Estonian manufacturing industry," Agronomy Research, vol. 13, no. 3, pp.792-809, 2015.

[7] Õ. Paas, Reinhold, K., and P: Tint, "OHSAS 18001 contribution to real and formal safety elements of safety management in manufacturing companies: results of statistical analysis, " Agronomy Research, vol.13, no.5, 2015, pp.1260-1274.

[8] R. Muthuviknesh, and K. A. Kumar, "The effect of occupational health and safety management on work environment: a prospective study," International Journal of Advance Research in Computer Science and Management Studies, vol. 2, no. 6, pp. 63-70, 2014.

[9] S. M: Zin, and F. Ismail, "Employers' behavioural safety compliance factors toward occupational, safety and health improvement in the construction industry," Procedia, Social and Behavioural Sciences, vol. 36, pp.742-751, 2012.

[10] S. Gautam, J. Maiti, A. Suamsundar, and S. Sarkar, "Segmented point process models for work system safety analysis," Safety Science, vol. 95, pp. 15-27, 2017.

[11] I.N. Isik, and E. Atasoylu, "Occupational safety and health in North Cyprus: evaluation of risk assessment," Safety Science, vol. 94, pp. 17-25, 2017.

[12] E. Tompa, C. Kalcevich, M. Foley, C. Mcleod, S. HoggJohnson, K. Cullen, E. MacEachen, G. Mahood, and E. Irvin, "A systematic literature review of the effectiveness of occupational health and safety regulatory enforcement," American Journal of Industrial Medicine, vol. 59, pp. 919933, 2016.

[13] S. M. Kyaw-Myint, L. Strazdins, M. Clements, P. Butterworth, and L. Gallagher, "A method of identifying health-based benchmarks for psychosocial risks," Safety Science, vol. 93, pp. 143-151, 2017.

[14] M. A. Gopang, M. Nebhwani, A. Khatri, and H. B. Marri, "An assessment of occupational health and safety measures and performance of SMEs: an empirical study," Safety Science, vol. 93, pp. 127-133, 2017.

[15] J. E. Karlsen, P.H. Lindoe, "The Nordic OHS model at a turning point?" Policy and Practice in Health and Safety, vol. 4, no.1, pp.17-30, 2016.

[16] A. Kuusisto. "Safety management systems: audit tools and reliability of auditing," $\mathrm{PhD}$ thesis, Tampere University of Technology, Tampere, Finland, 2000.

[17] A. A. Kadir, S. Sarip, N.H. N. Mahmood, S. M. Yusof, M. Z. Hassan, M. Y. Md. Daud and S. S. Aziz, "A review of integrated management system in the offshore oil and gas industry," Journal of Advanced Review on Scientific Research, vol. 12, no.1, pp. 11-25, 2015.

[18] A. Field, "Discovering statistics using IBM statistics. Fourth edition. SAGE Publications Ltd., [Online]. Available: http://www.uk.sagepub.com/field4e/main.htm. [Accessed Aug.2016].

[19] OHS Act (Occupational Health and Safety Act of Estonia). Passed 16.06.1999. State Gazette of Estonia, RTI 1999, 60, 616.

[20] M. O'Toole, “The relationship between employees' perceptions of safety and organizational culture. Journal of Safety Research, vol. 33, pp. 231-243, 2002.

[21] D. M. DeJoy, L: J. Della, R.J. Vanderberg, and M.G. Wilson, "Making work safer: testing a model of social exchange and safety management," Journal of Safety Research, vol. 41, pp.163-171, 2010.

[22] A. Neal, M.A. Griffin, and P. M. Hart., "The impact of organizational climate on safety climate and individual behaviour," Safety Science, vol. 34, pp. 99-109, 2000. 